\title{
Análise da operação de sedimentação em fermentação alcoólica
}

\author{
Alexsander Saves dos Santos ${ }^{1}$ \\ Ana Paula Mendes ${ }^{2}$ \\ Joycielle Naira dos Santos ${ }^{3}$ \\ Milena Baroni de Arruda $^{4}$
}

\begin{abstract}
RESUMO
A sedimentação é uma das operações unitárias utilizadas em processo de fermentação alcóolica. O sedimentador é mais indicado para leveduras que possuem características floculantes. Assim, este projeto teve o objetivo de confeccionar um sedimentador para separar a levedura do vinho, após todo o seu processo fermentativo. Foi desenvolvido o projeto de sedimentação utilizando recursos próprios, estabelecidos e providenciados nas proporções adequadas para o funcionamento do protótipo. Conforme testes, confirmou-se a eficácia do sedimentador por meio de análise de concentração de sólidos sedimentáveis, na qual obteve-se um aumento de $18 \%$ da concentração inicial.
\end{abstract}

Palavras-chave: Sedimentador. Fermentação. Concentração.

\footnotetext{
${ }^{1}$ Graduado em Física pelo Centro Universitário de Votuporanga - UNIFEV e em Pedagogia pela Faculdade da Aldeia de Carapicuíba - FALC. Mestre em Ciências Ambientais pela Universidade Brasil, ICESP. É professor nos Cursos de Engenharia Química e Medicina da Universidade Brasil, ICESP, Campus Fernandópolis, SP, Brasil. E-mail: saves.santos@gmail.com.

${ }^{2}$ Graduada em Tecnologia de Produção Sucroalcooleira pelo Centro Universitário de Votuporanga - UNIFEV. Atualmente é Graduanda em Engenharia Química pela Universidade Brasil, ICESP, Campus Fernandópolis, SP, Brasil. E-mail: anapaulamendes_10@outlook.com.

${ }^{3}$ Graduanda em Engenharia Química pela Universidade Brasil, ICESP, Campus Fernandópolis, SP, Brasil. Email: joyci.eng.quimica@outlook.com.

${ }^{4}$ Graduanda em Engenharia Química pela Universidade Brasil, ICESP, Campus Fernandópolis, SP, Brasil. Email: milena_baroni_arruda@hotmail.com.
} 


\title{
Analysis of the sedimentation operation in alcoholic fermentation
}

\begin{abstract}
Sedimentation is one of the unit operations used in the alcoholic fermentation process. The sedimenter is more suitable for yeasts that have flocculating characteristics. Thus, this project had the objective of making a sedimentator to separate the yeast from the wine, after all its fermentation process. The sedimentation project was developed using its own resources, established and provided in adequate proportions for the prototype to function. According to tests, the effectiveness of the sedimenter was confirmed through analysis of the concentration of sedimentable solids, in which an increase of $18 \%$ in the initial concentration was obtained.
\end{abstract}

Keywords: Sedimentator. Fermentation. Concentration.

Artigo recebido em: 19/02/2021

Aceito em: 31/05/2021 


\section{INTRODUÇÃO}

Os fundamentos aplicados ao Processo de Separação estão intimamente ligados aos de Operações Unitárias. Este conceito foi introduzido por Arthur D. Little em 1915 e foi essencial para a sistematização do ensino dos Processos Químicos (BABIC; PFENNIG, 2006). De uma forma geral, as Operações Unitárias envolvem apenas as etapas físicas de um processo industrial, não abrangendo a ocorrência de transformações químicas (COSTA, 2015).

São cada vez maiores os números de Operações Unitárias que se usam em processos de fabricação, podendo-se aludir, dentre eles, ao de Operações baseadas em Transferência da Quantidade de Movimento - que retrata métodos do processo em questão: a sedimentação (PFENNIG, 2004).

O processo de sedimentação é aplicado em misturas de sólidos em suspensão e, tratase de um processo lento. Ele é baseado em deixar uma mistura repousando para que as fases sejam separadas, sendo que a fase mais espessa deposita-se no fundo do recipiente e as demais também vão se depositando sucessivamente até que a fase menos densa fique na superfície. Se necessário o manejo do recipiente, deverá ser feito cuidadosamente para que as fases não voltem a se misturar e seja possível remover os componentes de cada fase da mistura individualmente. Segundo Arouca (2007) a separação das fases sólida e líquida pelo fenômeno da sedimentação ocorre basicamente pela diferença das densidades dos constituintes e pela ação da força gravitacional.

De acordo com Medeiros (2016) o processo de sedimentação é aplicado quando a concentração das partículas na mistura é superior a $40 \%$ da razão v/v; e o tempo de espera no processo de sedimentação é menor que no processo de decantação.

Em testes de sedimentação de soluções concentradas, é perceptível a formação de interfaces e regiões de diferentes concentrações de sólidos. Foust et al. (1982) citam que em tais condições podem ser definidas até quatro diferentes zonas de concentração: líquido límpido, concentração uniforme, zona de dimensões e concentrações variáveis, e sólidos grossos. Já na decantação de soluções diluídas não é possível tal diferenciação. As únicas fases perceptíveis são o depósito de sólidos ao fundo em si.

Quanto ao processo, a sedimentação pode ser classificada como forma batelada ou contínua. Em um sedimentador contínuo, distinguem-se duas regiões: a de sedimentação 
livre, onde a velocidade de decantação é função apenas da concentração de sólidos local; e a região de espessamento, onde a velocidade de decantação depende da concentração de sólidos e da profundidade, não se aplicando os resultados de um teste simples de proveta.

$\mathrm{Na}$ forma batelada, a uma dada posição de um ensaio realizado em proveta, a concentração dos sólidos e a velocidade de decantação variam continuamente ao longo do tempo. Essa forma pode ser usada para a obtenção da função de velocidade de decantação versus concentração de sólidos.

Conforme Novaes (2005), em aplicações de maiores escalas, o método natural é inviável devido ao tempo de espera necessário para a concretização do processo em cada amostra tornando jus a sedimentação forçada. Uma possibilidade é a utilização de centrífugas, pois aceleram a sedimentação das células suspensas no meio líquido através da gravidade por ação de um campo gravitacional centrífugo, dando origem a suspensões mais concentradas, que se baseiam na diferença de densidades existentes entre as células e o meio líquido (CAMPOS, 2013).

Outra opção, de acordo com a variante de necessidade da empresa, é a dosagem de produtos químicos na matéria a ser sedimentada. Isso acontece com auxílio de um tanque sedimentador (local para onde a matéria é bombeada e, posteriormente, o produto químico dosado). Esses tipos de tanques atuam como espessadores ou clarificadores. No primeiro caso, a fase que interessa é o líquido límpido; no segundo, a fase que interessa é a chamada "lama" (NOVAES, 2005).

A floculação consiste em aglomerar as partículas através da força de Van Der Waals (força de atração entre as moléculas), dando origem a flocos maiores que as partículas isoladas (CARVALHO; SOUZA; ZEMPULSKI, 2015).

Agentes coagulantes eficientes devem ser capazes de produzir espécies catiônicas em solução, promovendo a desestabilização das partículas do meio através de neutralização/redução de cargas. Floculantes tem como objetivo básico promover a formação de flocos e agregados maiores e mais densos, favorecendo sua remoção em etapas posteriores do processo de tratamento, tais como sedimentação e filtração (JÚNIOR; ABREU, 2018)

Outra aplicação eficaz para que a sedimentação aconteça dispondo de menor tempo é a utilização de polímeros - que atuam como aglomerantes das pequenas partículas da floculação, elevando o peso. Para amostras com potencial hidrogeniônico entre 5 e 7 , são 
manipulados polímeros de caráter catiônico, enquanto, em casos de potenciais hidrogeniônicos maiores que 7, os polímeros empregados devem ser de caráter aniônico.

O tanque de sedimentação clássico (Figura 1), também chamado de sedimentador contínuo convencional, dispõe de dutos de alimentação da suspensão, de retirada do clarificado (overflow) e do espessado (underflow). Esse tipo de sedimentador é dotado de raspadores que auxiliam no descarte do espessado.

Figura 1: Esquema de um sedimentador contínuo convencional

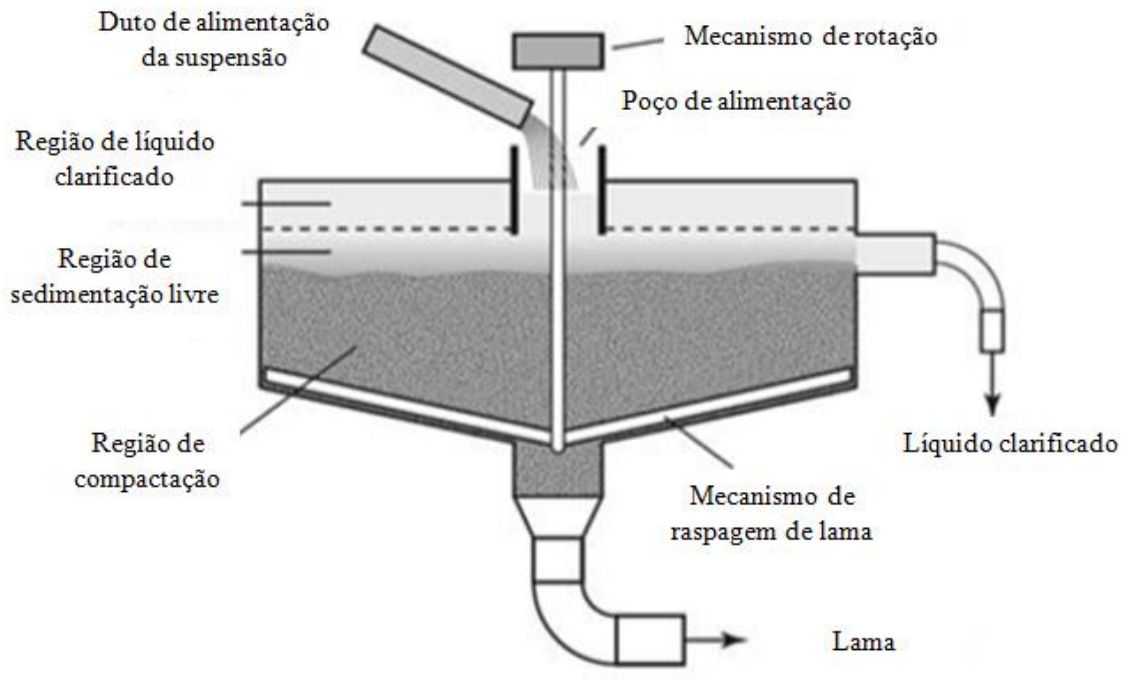

Fonte: CREMASCO (2012).

A inclusão de lamelas para aumentar a região de compactação sem modificar o diâmetro do sedimentador contínuo convencional dá origem ao sedimentador de alta capacidade, também chamado de sedimentador de lamela (Figura 2). Este equipamento apresenta um conjunto de placas inclinadas (lamelas) com um espaço entre si, de modo a formar canais preferenciais para o escoamento da suspensão. Por sua vez, a suspensão pode ser alimentada diretamente no compartimento da alimentação ou na câmara de mistura de floculação. As partículas sedimentam sobre as lamelas e deslizam até o fundo do equipamento, dando origem a lama que será bombeada ou transportada até a unidade armazenadora (CREMASCO, 2012).

Para o escoamento e retirada de suspensões concentradas de acordo com Cremasco (2012), o sedimentador apresenta um sistema de vibração em substituição aos raspadores rotativos dos espaçadores convencionais. Esse tipo de equipamento é utilizado na separação de finos de carvão, de minério de ferro, de ouro, tratamento de água entre outras aplicações. 
Figura 2: Esquema de um sedimentador lamelado

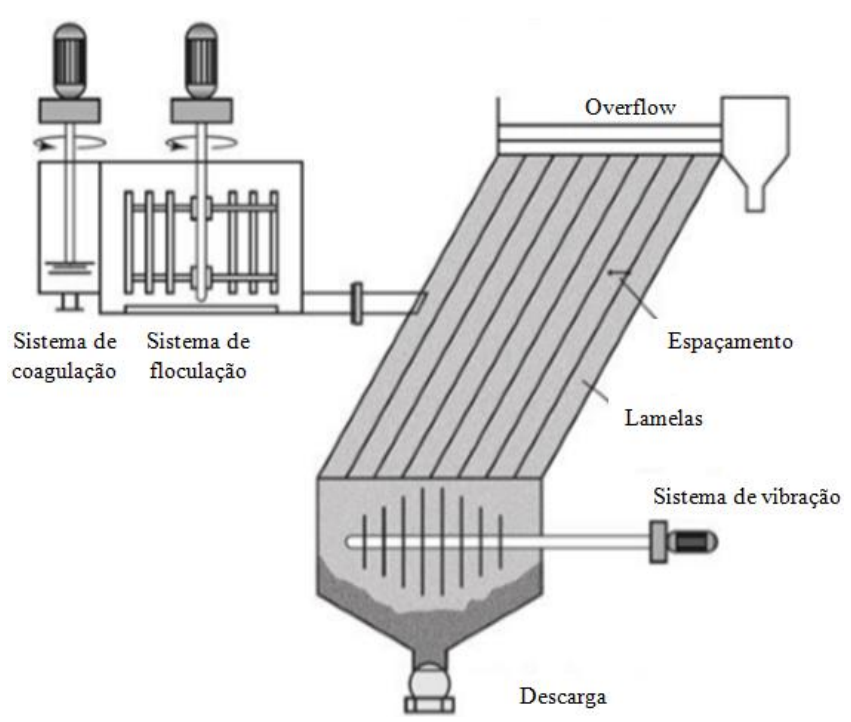

Fonte: CREMASCO (2012).

Já a fermentação é um processo químico, com ausência de gás oxigênio $\left(\mathrm{O}_{2}\right)$, no qual fungos e bactérias realizam a transformação de matéria orgânica em outros produtos e energia. É a forma que esses seres encontram de produzir energia para o desempenho de suas funções biológicas.

Podemos dizer que a fermentação é uma via de produção energética que utiliza uma matéria orgânica, como a glicose. Antes da fermentação ocorrer, um processo denominado de glicólise é realizado. Para a fermentação alcóolica, o microorganismo mais comum é a levedura Saccharomyces Cerevisiae (Figura 3) - microrganismo aeróbio facultativo, isto é, que tem a habilidade de se ajustar metabolicamente, tanto em condições de aerobiose como de anaerobiose (ALCARDE, 2017).

Nesse processo aeróbio facultativo, os produtos finais do metabolismo do açúcar irão depender das condições ambientais em que a levedura se encontra. Assim, em aerobiose, o açúcar é transformado em biomassa, $\mathrm{CO}_{2}$ e água; e, em anaerobiose, a maior parte é convertida em etanol e $\mathrm{CO}_{2}$, processo denominado de fermentação alcoólica.

As leveduras $S$. Cerevisiae são elípticas, medindo cerca de 6 a $8 \mathrm{~mm}$ de comprimento por $5 \mu \mathrm{m}$ de largura. Reproduzem-se assexuadamente por brotamento (ou gemulação). Sendo a temperatura ótima de seu crescimento entre 20 e $30^{\circ} \mathrm{C}$, com o pH entre 4,5 e 5,5 (ALCARDE, 2017). 
Figura 3: Levedura Saccharomyces Cerevisiae

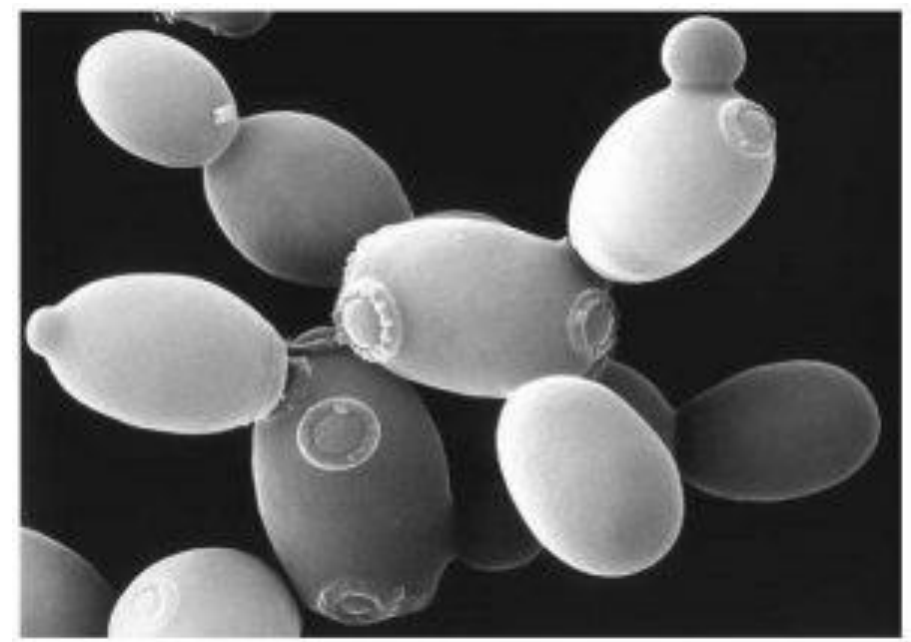

Fonte: MADIGAN (2010).

A S. Cerevisiae destaca-se como a espécie mais explorada comercialmente entre as leveduras e apresenta grande emprego na indústria para a fabricação de vários produtos. Em relação a outras leveduras, a $S$. Cerevisiae apresenta fácil isolamento e manutenção, pouca exigência nutricional, bom crescimento em meios constituídos por resíduos industriais e amplo uso em processos industriais (podendo ser usada na produção de bebidas alcoólicas, vitaminas, fermento de pão, cosméticos, enzimas, macromoléculas etc.) (COELHO, 2013).

De acordo com Alcarde (2017), para ocorrer a fermentação alcóolica, a levedura é alimentada com mosto - líquido açucarado que constitui uma correção dos açúcares totais por meio de diluição e que pode ser fermentado. Quanto ao tempo de fermentação, pode variar entre 6 e 12 horas (CRUZ, 2019).

Após o processo de fermentação, a levedura pode ser recuperada por centrifugação ou sedimentação. A sedimentação, como neste caso, consiste na espera da precipitação natural das leveduras após a fermentação. Assim que os açúcares se esgotam da mistura açucarada em fermentação, o vinho é enviado aos sedimentadores, onde ocorre a separação: de um lado o leite de levedura e, do outro, o vinho delevedurado (ALCARDE, 2017).

Há um novo processo de fermentação alcoólica, intitulada como tecnologia VHG (Very High Gravity), sigla em inglês que faz referência à alta concentração de açúcares no caldo fermentativo. Trata-se de uma fermentação alcoólica com reciclo de células, voltada à obtenção de vinhos de alto teor alcoólico. A produção de vinhaça durante a fermentação VHG é reduzida devido à maior taxa de conversão alcóolica, diminuindo o custo de produção de etanol (CRUZ, 2019). 
Tendo em vista o exposto anteriormente e a relevância nos processos industriais, este trabalho visa desenvolver, com baixo custo, um equipamento de sedimentação de pequena escala e com ciclo contínuo para recuperação do fermento após processo fermentativo, que permitirá o retorno do fermento para um novo processo de fermentação.

\section{METODOLOGIA}

O presente projeto foi desenvolvido na Universidade Brasil, campus Fernandópolis SP. Em primeira instância, optou-se por um projeto de sedimentação em escala industrial, baseado em uma indústria sucroalcooleira da região, a qual, por suas normas internas, não autorizou sua citação, porém forneceu apoio e colaborou com testes voltados ao projeto.

O desenvolvimento deste projeto seguiu as etapas elencadas na Figura 4:

Figura 4: Etapas de desenvolvimento do projeto
Escolha do
Seleção dos
Montagem
materiais
Testes de
Avaliação de
do protótipo
funcionamento
desempenho

Fonte: Autoria própria (2019).

Montou-se o protótipo, considerando os custos mencionados na Tabela 1.

Tabela 1: Custo dos materiais aplicados

\begin{tabular}{|c|c|c|c|c|c|}
\hline Material & Quantidade & & nitário & & Valor Total \\
\hline Placa de Vidro 20 x $13 \mathrm{~cm}$ & 4 & \multirow{5}{*}{$\mathrm{R} \$$} & \multirow{5}{*}{130,00} & \multirow{5}{*}{$\mathrm{R} \$$} & \multirow{5}{*}{130,00} \\
\hline Placa de Vidro 13 x $13 \mathrm{~cm}$ & 1 & & & & \\
\hline Placa de Vidro 15 x $10 \mathrm{~cm}$ & 4 & & & & \\
\hline Placa de Vidro 10 x $10 \mathrm{~cm}$ & 2 & & & & \\
\hline Placa de Vidro 10 x $11 \mathrm{~cm}$ & 4 & & & & \\
\hline Silicone branco Wurth $180 \mathrm{~g}$ & 2 & $\mathrm{R} \$$ & 23,90 & $\mathrm{R} \$$ & 47,80 \\
\hline Cantoneira Branca $3 / 4$ & $3 \mathrm{~m}$ & $\mathrm{R} \$$ & 13,00 & $\mathrm{R} \$$ & 39,00 \\
\hline
\end{tabular}




\begin{tabular}{|c|c|c|c|c|c|}
\hline Material & Quantidade & \multicolumn{2}{|c|}{ Valor Unitário } & \multicolumn{2}{|c|}{ Valor Total } \\
\hline Abraçadeira $9 \mathrm{~mm}$ & 12 & $\mathrm{R} \$$ & 3,58 & $\mathrm{R} \$$ & 42,96 \\
\hline Registro Esfera Profield Remadi 3/4 & 2 & $\mathrm{R} \$$ & 17,60 & $\mathrm{R} \$$ & 35,20 \\
\hline Joelho interno duplo & 2 & $\mathrm{R} \$$ & 2,66 & $\mathrm{R} \$$ & 5,32 \\
\hline Adaptador interno 3/4"x1/2" & 8 & $\mathrm{R} \$$ & 2,15 & $\mathrm{R} \$$ & 17,20 \\
\hline Aplicador de Silicone & 1 & $\mathrm{R} \$$ & 24,00 & $\mathrm{R} \$$ & 24,00 \\
\hline Lâmina Serra Metal & 1 & $\mathrm{R} \$$ & 4,40 & $\mathrm{R} \$$ & 4,40 \\
\hline Mangueira Cristal & $2 \mathrm{~m}$ & $\mathrm{R} \$$ & 5,30 & $\mathrm{R} \$$ & 10,60 \\
\hline Placa de MDF 90 x $40 \mathrm{~cm}$ & 1 & $\mathrm{R} \$$ & 25,00 & $\mathrm{R} \$$ & 25,00 \\
\hline Parafuso fenda-philipis & 32 & $\mathrm{R} \$$ & 0,15 & $\mathrm{R} \$$ & 4,80 \\
\hline Mini cantoneira & 16 & $\mathrm{R} \$$ & 0,50 & $\mathrm{R} \$$ & 8,00 \\
\hline Combustível & - & & & $\mathrm{R} \$$ & 70,00 \\
\hline \multirow[t]{2}{*}{ Projeto em 3D } & - & & & $\mathrm{R} \$$ & 30,00 \\
\hline & & & & $\mathbf{R} \$$ & 494,28 \\
\hline
\end{tabular}

Fonte: Autoria própria (2019).

Para desenvolver o projeto de sedimentação utilizaram-se recursos próprios, estabelecidos e providenciados nas proporções adequadas para o funcionamento do protótipo, como descrito no Quadro 1.

Quadro 1: Desenvolvimento do protótipo

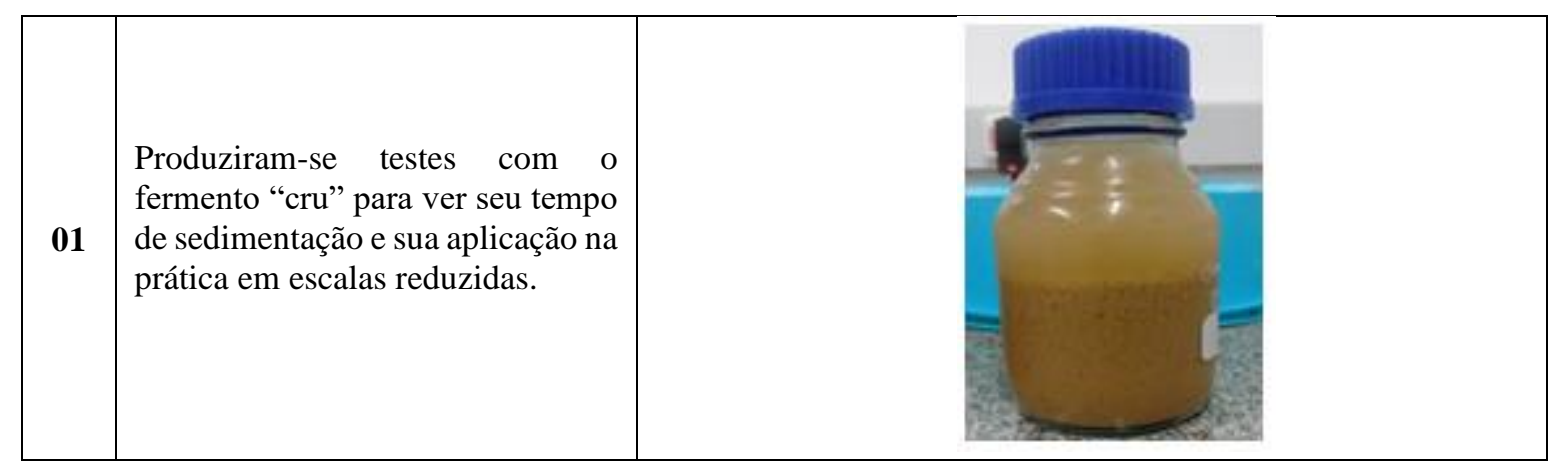

Continua... 


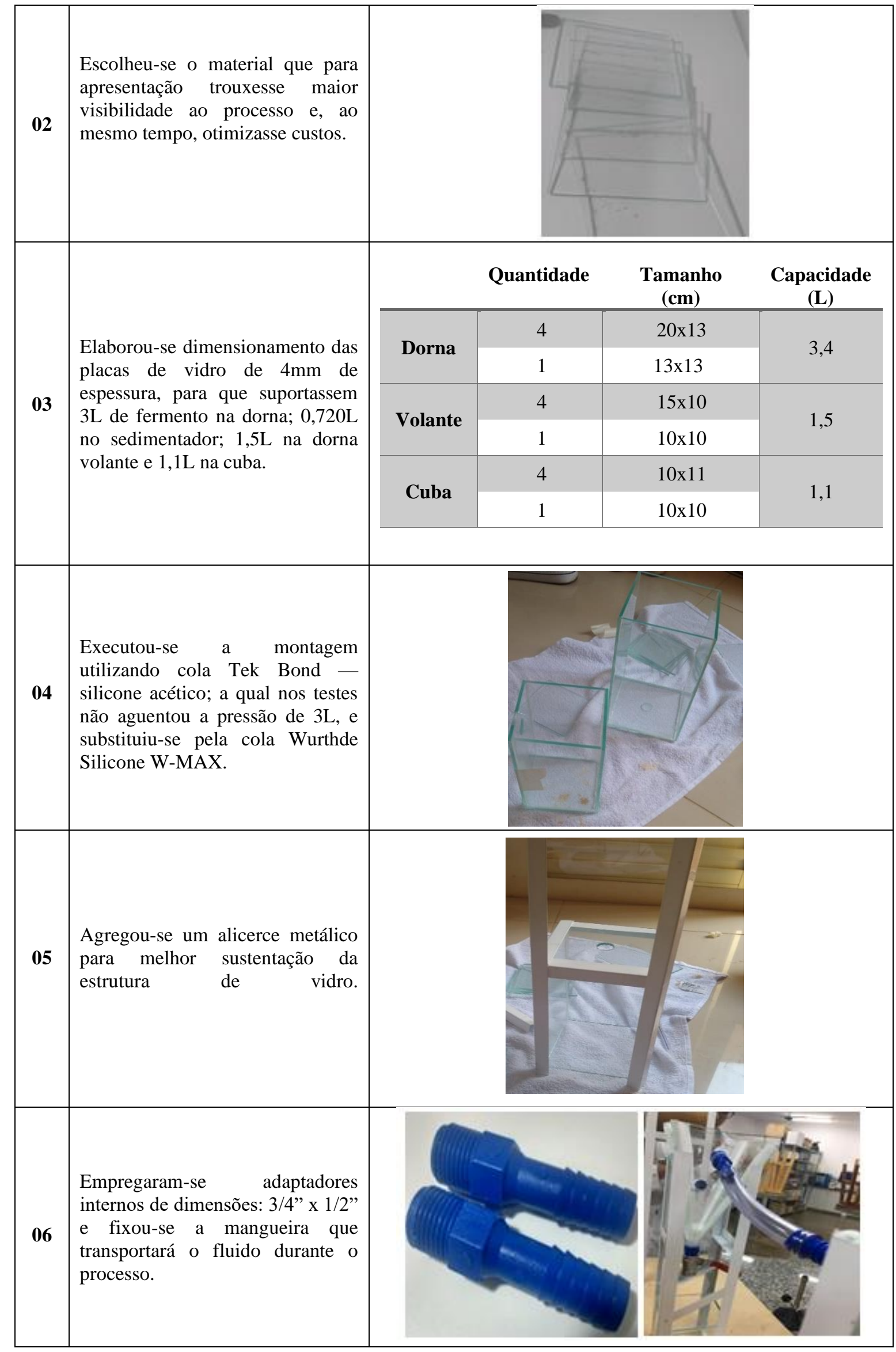

Continua... 


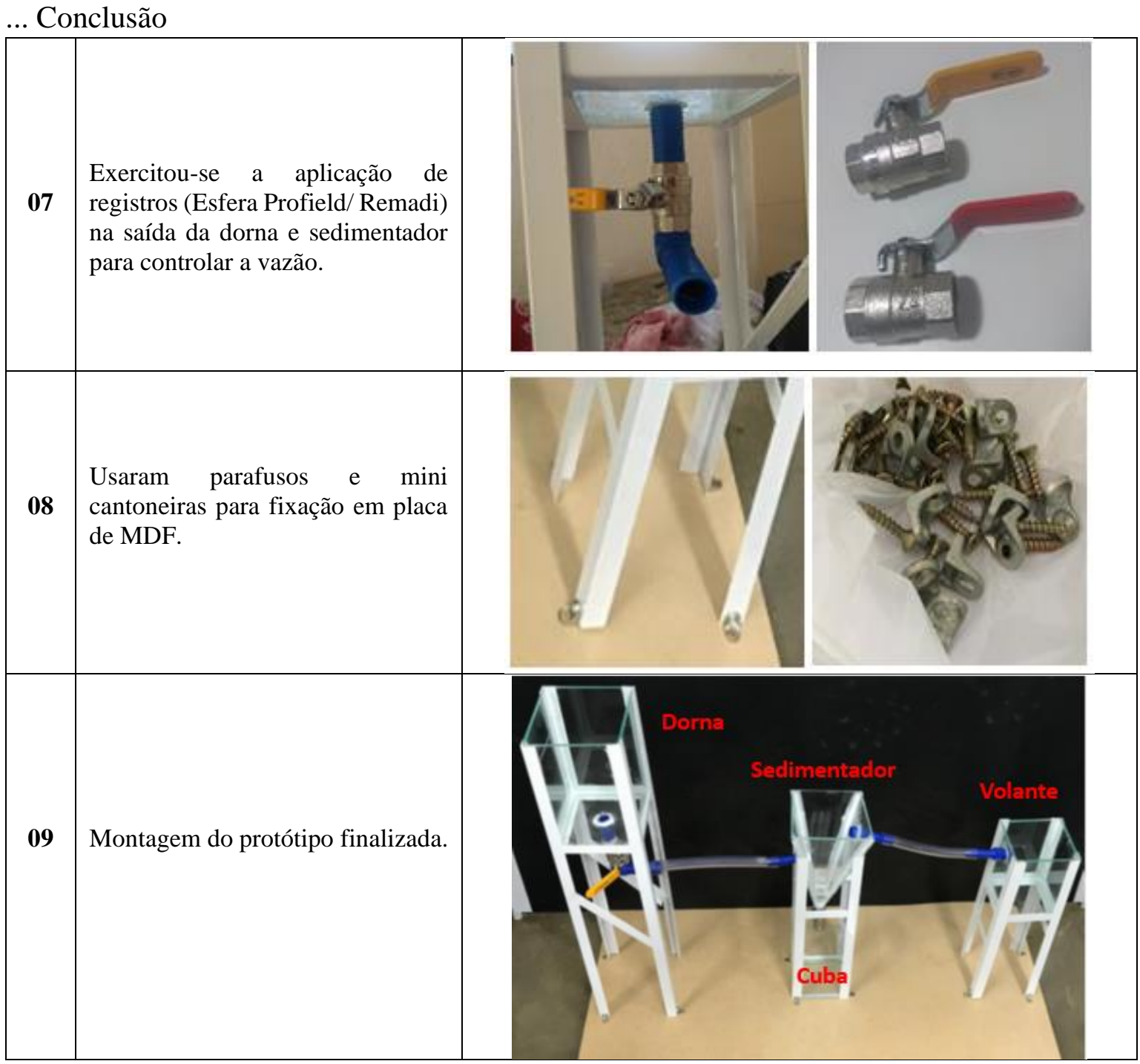

Fonte: Autoria própria (2019).

Obteve-se o fermento que foi sedimentado e testado no protótipo, através do processo de fermentação elaborado conforme Quadro 2.

Quadro 2: Processo de fermentação para obtenção de amostras de fermento a ser sedimentado

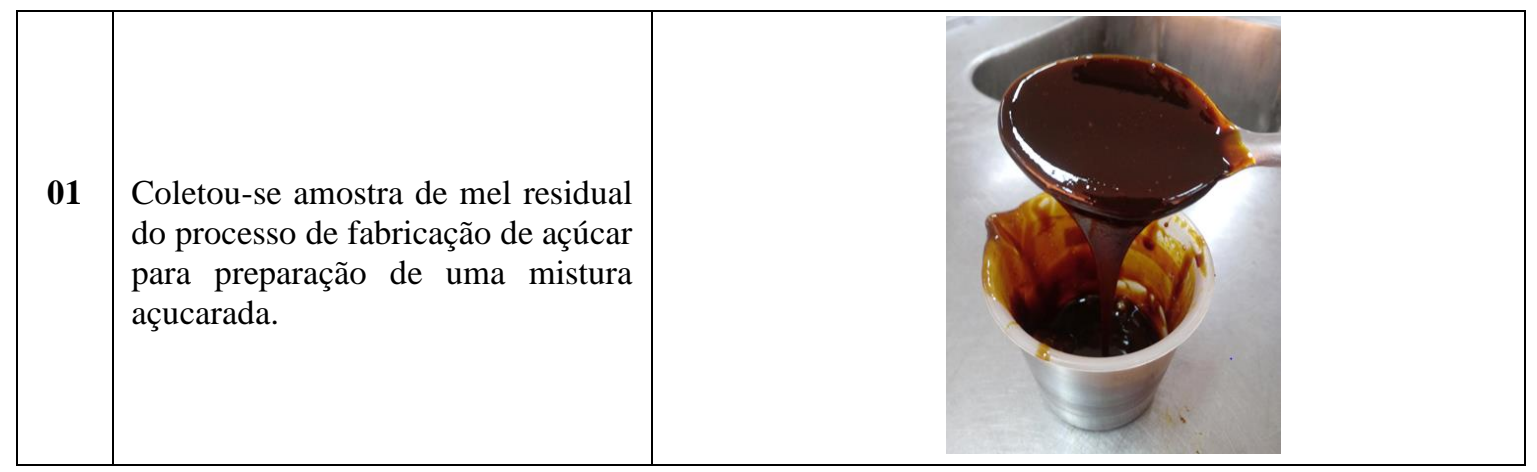

Continua... 


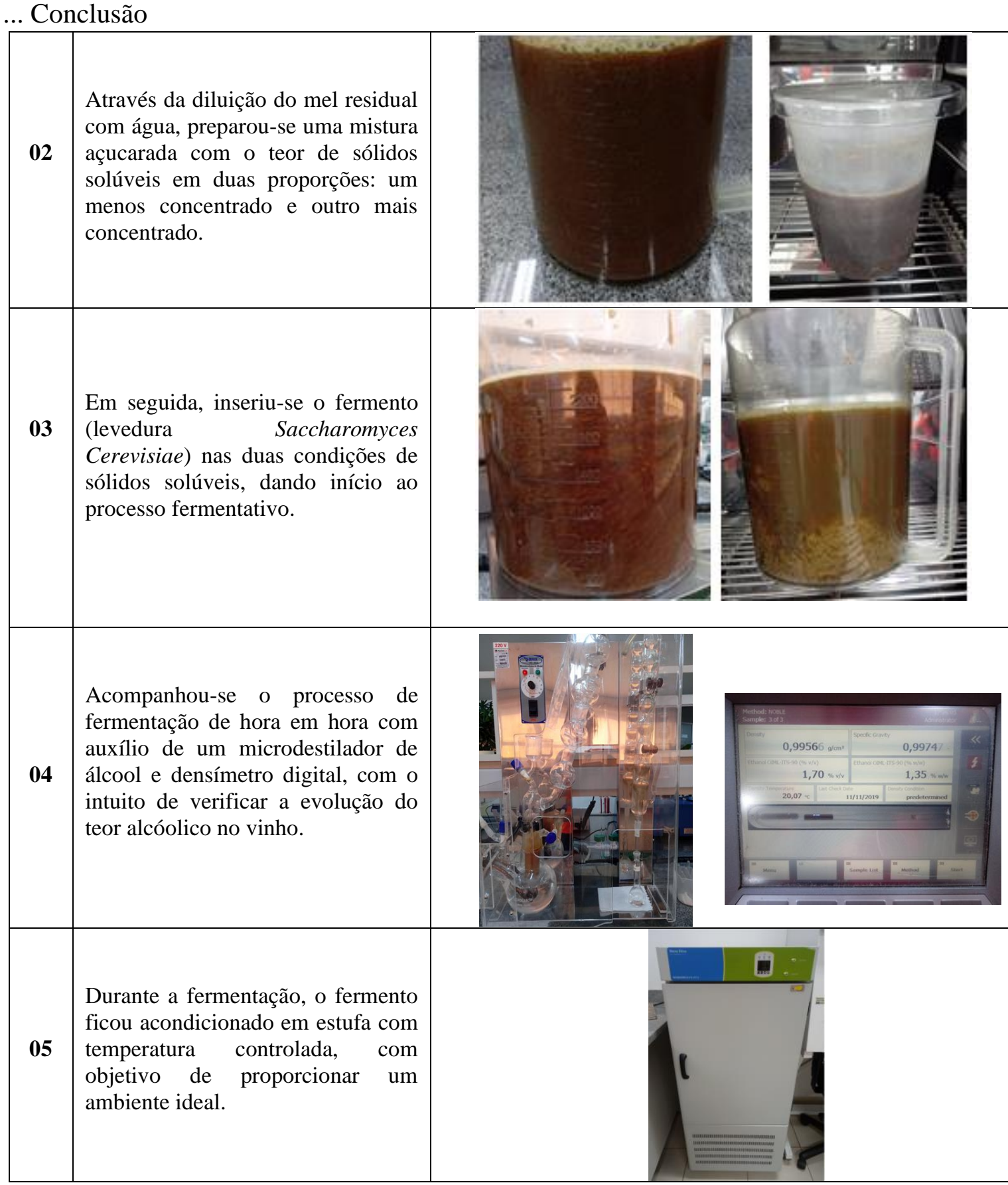

Fonte: Autoria própria (2019)

\section{RESULTADOS E DISCUSSÃO}

Para realizar o processo de sedimentação no protótipo construído e concretizar o bom funcionamento do mesmo, simulou-se um processo fermentativo. Para este processo fermentativo, utilizou-se uma levedura floculante com os dados analíticos citados na Tabela 2. Dados estes que foram obtidos com auxílio de um microscópio. 
Tabela 2: Resultados analíticos das leveduras utilizadas para o processo fermentativo

\begin{tabular}{cc}
\hline Análises & Resultados analíticos \\
\hline Viabilidade (\%) & 54,25 \\
\hline Brotamento $(\%)$ & 16,42 \\
\hline Levedura $/ \mathrm{mL}$ & $4,38 \times 10^{8}$ \\
\hline Bastonetes $/ \mathrm{mL}$ & $2,05 \times 10^{5}$ \\
\hline
\end{tabular}

Fonte: Autoria própria (2019).

A Figura 5 mostra o formato das leveduras utilizadas no teste de fermentação alcóolica.

Figura 5: Vista pelo microscópio das leveduras vivas (transparentes) e mortas (rosadas)

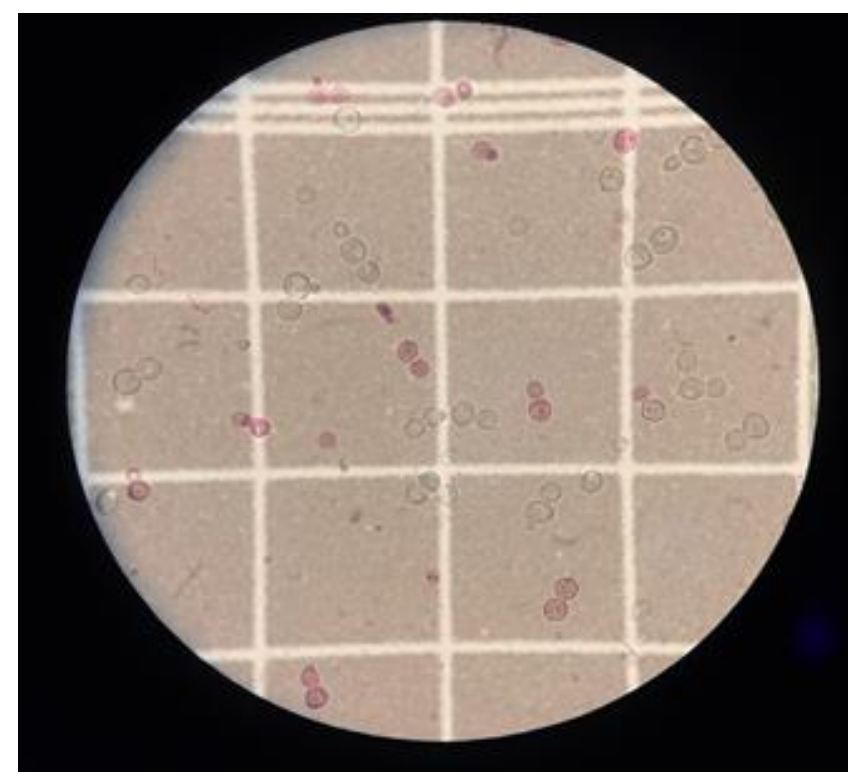

Fonte: Autoria própria (2019).

Para o processo fermentativo, preparou-se uma mistura de fermento com solução açucarada na proporção respectiva de 30 e $70 \%$ do volume total da dorna, considerando uma margem de segurança. Elaboraram-se duas linhas de fermentação de misturas açucaradas com concentrações distintas, ou seja, uma delas com teor de sólidos solúveis de 10,07 (linha 1) e a outra com $19,55^{\circ}$ (linha 2). Com auxílio de um microdestilador de álcool e um densímetro digital, acompanhou-se a evolução do processo fermentativo da levedura por meio do aumento gradativo do teor alcóolico no vinho, conforme Tabela 3. Este processo fermentativo levou em torno de 8 horas para concluir a fermentação, conforme tempo indicado por Cruz (2019). 
Tabela 3: Acompanhamento da evolução do teor alcóolico durante a fermentação

\begin{tabular}{|c|c|c|c|}
\hline \multicolumn{2}{|c|}{ Linha fermentação 1 } & \multicolumn{2}{c|}{ Linha fermentação 2 } \\
\hline $\begin{array}{c}\text { Horas de } \\
\text { fermentação }\end{array}$ & $\begin{array}{c}\text { Teor alcóolico } \\
\left({ }^{\circ} \mathbf{G L}\right)\end{array}$ & $\begin{array}{c}\text { Horas de } \\
\text { fermentação }\end{array}$ & $\begin{array}{c}\text { Teor alcóolico } \\
\left({ }^{\circ} \mathbf{G L}\right)\end{array}$ \\
\hline $\mathbf{0 1 : 0 0}$ & 0,12 & $\mathbf{0 1 : 0 0}$ & 0,62 \\
\hline $\mathbf{0 2 : 0 0}$ & 0,48 & $\mathbf{0 2 : 0 0}$ & 1,38 \\
\hline $\mathbf{0 3 : 0 0}$ & 1,48 & $\mathbf{0 3 : 0 0}$ & 2,24 \\
\hline $\mathbf{0 4 : 0 0}$ & 1,54 & $\mathbf{0 4 : 0 0}$ & 3,58 \\
\hline $\mathbf{0 5 : 0 0}$ & 2,22 & $\mathbf{0 5 : 0 0}$ & 4,80 \\
\hline $\mathbf{0 6 : 0 0}$ & 3,18 & $\mathbf{0 6 : 0 0}$ & 5,76 \\
\hline $\mathbf{0 7 : 0 0}$ & 3,32 & $\mathbf{0 7 : 0 0}$ & 6,20 \\
\hline $\mathbf{0 8 : 0 0}$ & 3,40 & $\mathbf{0 8 : 0 0}$ & 6,40 \\
\hline
\end{tabular}

Fonte: Autoria própria (2019).

Os dados da Tabela 3 indicaram o ponto final da fermentação e comprovaram a informação de Cruz (2019), pois, para a elevação do teor alcóolico no vinho, é necessário maior concentração de sólidos solúveis na mistura açucarada para fermentação, em que se obteve na linha 2 um teor alcóolico de $6,40^{\circ}$, superior a $3,40^{\circ}$ da linha 1 , devido à concentração dos sólidos solúveis estar maior que na linha 1.

Tendo em vista o tempo do processo fermentativo de 8 horas e não havendo mais aumento do teor alcóolico do vinho de forma considerável, concluiu-se que o processo de fermentação chegara ao fim, e que a mistura fermentada estava pronta para a fase de sedimentação no protótipo construído.

Antes de avaliar a eficiência de sedimentação no protótipo com a mistura fermentada, o mesmo foi testado (utilizando água como referência), para detectar possíveis vazamentos nos pontos de conexão. No teste, detectaram-se dois escapes na área inferior do projeto, sendo um no conector da dorna e o outro no conector do sedimentador, conforme Figura 6. Com auxílio de uma cola de silicone, os vazamentos foram solucionados. 
Figura 6: Detecção de vazamento no teste realizado com água

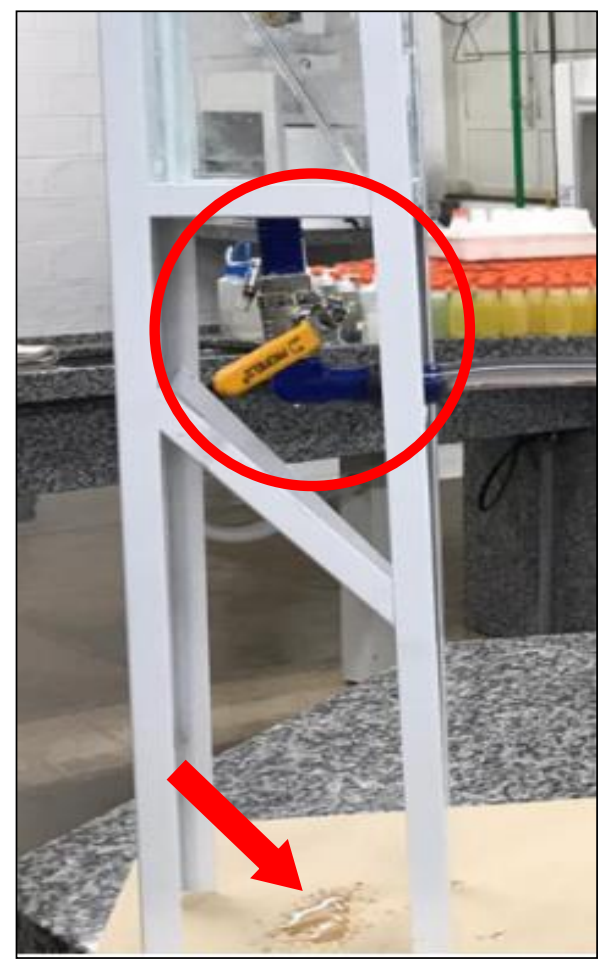

Fonte: Autoria própria (2019).

Logo após, conduziu-se a mistura fermentada ao protótipo e seguiu-se com o processo de sedimentação para recuperação do fermento. Processo este que contemplou os seguintes trajetos (conforme Figura 7): transferiu-se a mistura fermentada para a dorna; em processo contínuo e com controle de vazão, a mistura seguiu para o sedimentador. No sedimentador por conta da gravidade, o fermento que é mais denso foi se depositando ao fundo e, aos poucos, foi sendo retirado pela cuba. Já o sobrenadante que ficou no sedimentador, que é o vinho, foi recolhido na volante.

O controle de vazão pela abertura das válvulas foi de extrema importância, pois como foi simulado um processo contínuo, teve-se que manter uma vazão controlada a tempo de sedimentar o fermento, e ao mesmo tempo ir retirando-o lentamente pela cuba para não misturar as fases que já haviam se separado.

Figura 7: Percurso para sedimentação por meio do protótipo 


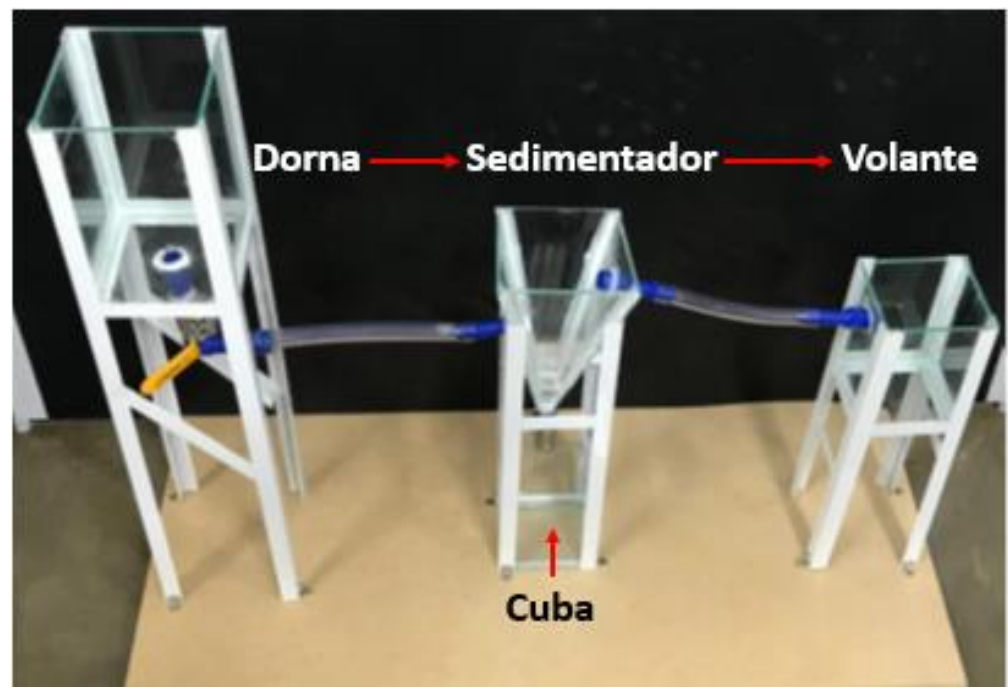

Fonte: Autoria própria (2019).

Determinou-se a vazão do percurso da dorna para o sedimentador, como também do sedimentador para a volante. Para isso, com auxílio de um temporizador, cronometrou-se o tempo que a mistura levou para percorrer de um compartimento a outro, como também mediu-se o volume que ficou retido em cada compartimento. E, assim, foi possível apurar usando a Equação 1, a vazão de ambos esses percursos, que tiveram os resultados mencionados na Tabela 4.

$$
Q_{v}=\frac{V}{T}
$$

em que, $Q_{v}$ é a vazão volumétrica $\left(\mathrm{m}^{3} / \mathrm{s}\right), V$ é o volume $\left(\mathrm{m}^{3}\right)$ e $T$ é o tempo (s).

Tabela 4: Vazões volumétricas obtidas durante processo de sedimentação

\begin{tabular}{c|c|c|c}
\hline \multicolumn{2}{c|}{ Fórmula Aplicada } & Substituição & Resultado $\left(\mathbf{m}^{3} / \mathbf{s}\right)$ \\
\hline $\begin{array}{c}\text { Vazão da dorna para } \\
\text { sedimentador }\end{array}$ & $Q_{v}=\frac{\operatorname{Volume}\left(\mathrm{m}^{3}\right)}{\operatorname{Tempo}(s)}$ & $Q_{v}=\frac{0,002}{60}$ & $3,33 \times 10^{-5}$ \\
\hline $\begin{array}{c}\text { Vazão do } \\
\text { sedimentador para a } \\
\text { volante }\end{array}$ & $Q_{v}=\frac{\operatorname{Volume}\left(\mathrm{m}^{3}\right)}{\operatorname{Tempo}(s)}$ & $Q_{v}=\frac{0,0006}{226}$ & $2,65 \times 10^{-6}$ \\
\hline
\end{tabular}

Fonte: Autoria própria (2019).

A vazão do sedimentador para a volante $\left(2,65 \times 10^{-6} \mathrm{~m}^{3} / \mathrm{s}\right)$ foi menor comparando com a vazão da dorna para o sedimentador $\left(3,33 \times 10^{-5} \mathrm{~m}^{3} / \mathrm{s}\right)$, pois, como se tratou de um processo 
contínuo, foi feita a retirada do sobrenadante e ao mesmo tempo a retirada pela cuba do fermento sedimentado.

A Figura 8 mostra o momento em que ocorreu a sedimentação no protótipo.

Figura 8: Sedimentação do fermento no protótipo

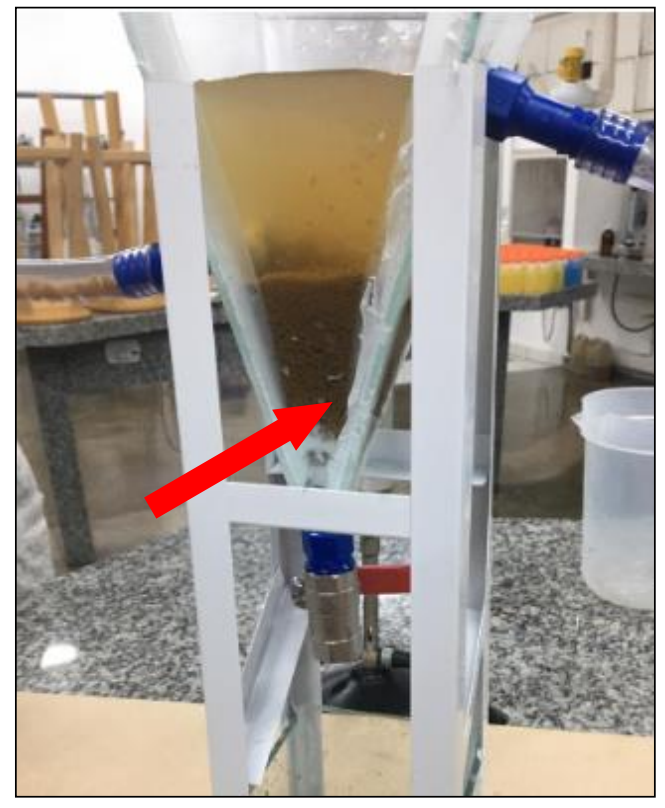

Fonte: Autoria própria (2019).

E, para certificar a eficiência do protótipo, reservaram-se duas amostras, sendo elas: uma amostra antes do processo de sedimentação e outra amostra que foi recolhida após o processo de sedimentação no protótipo. Em ambas as amostras coletadas, foi realizada a análise de concentração de sólidos sedimentáveis com auxílio de uma centrífuga (neste caso os sólidos sedimentáveis são o próprio fermento). E os resultados foram satisfatórios, pois a concentração inicial da mistura foi de 7\%, enquanto após a sedimentação no protótipo, a concentração alcançou 25\% (conforme Figura 9), ou seja, teve um aumento de 18\%, visto que o intuito do protótipo era demonstrar a recuperação do fermento através da sedimentação após um processo de fermentação alcóolica.

Figura 9: Resultados obtidos da concentração de sólidos sedimentáveis 


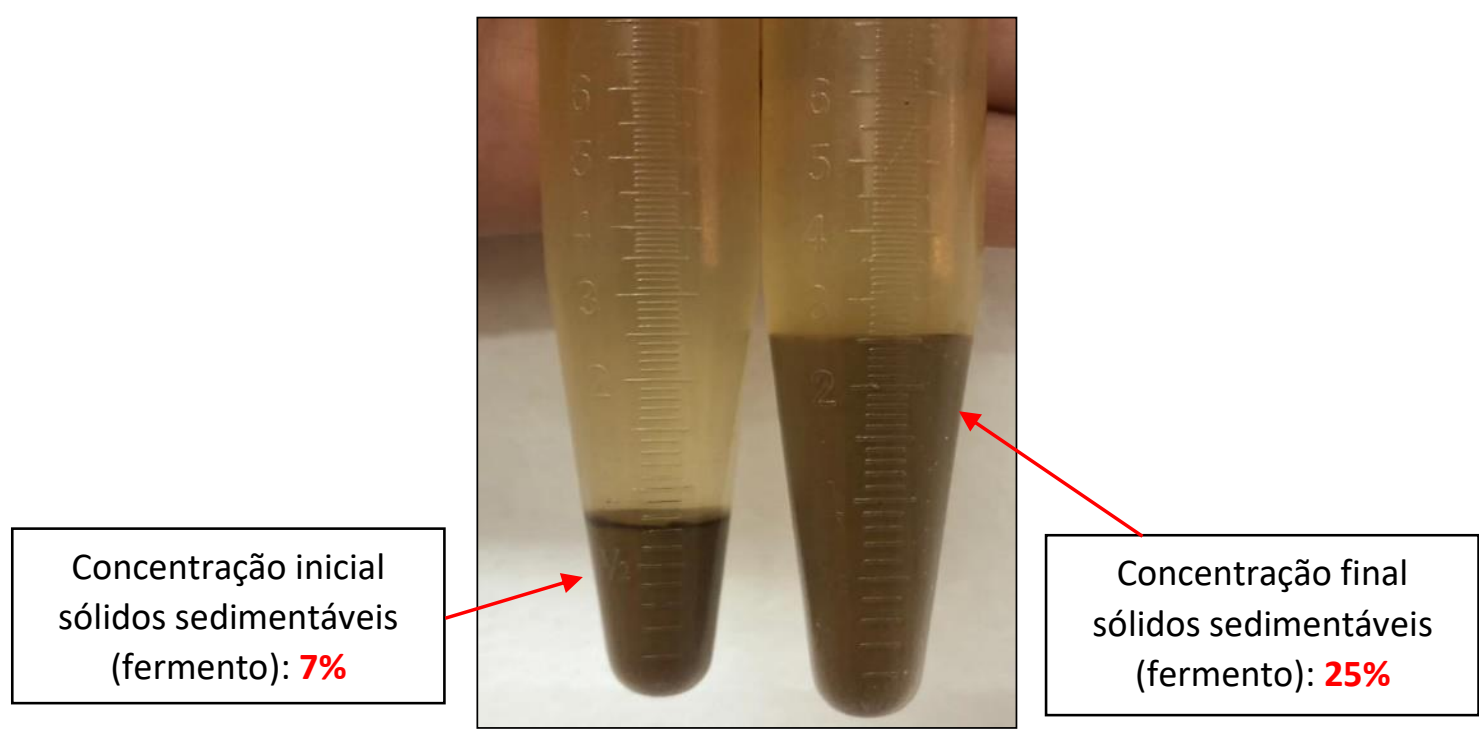

Fonte: Autoria própria (2019).

Vale ressaltar que, de acordo com Guidini (2013), "a levedura floculante tem uma característica importante, o qual permite que as células de levedura formem flocos e decantem facilmente no caldo fermentado". Essa afirmação foi comprovada, pois além do funcionamento do protótipo, a característica floculante da levedura utilizada foi importantíssima para os resultados obtidos.

Sendo assim, a realização do presente protótipo permitiu a melhor compreensão das atividades industriais do processo fermentativo que utilizam o processo de sedimentação. E, tendo como referência o artigo de Campos (2013), foi possível confirmar que essa etapa é de grande importância.

\section{CONCLUSÃO}

Com base no projeto elaborado e pelos resultados obtidos, certificou-se que o protótipo apresentou eficiência conforme esperado. Foi possível recuperar o fermento por meio de um processo de sedimentação, visto que se obteve o aumento da concentração de sólidos sedimentáveis de $7 \%$ para $25 \%$. Essa recuperação deve acontecer devido à necessidade de retornar as leveduras para um novo processo fermentativo e o líquido fermentado que, posteriormente, será encaminhado para a destilaria para a produção de etanol.

Verificou-se também, principalmente em uma perspectiva industrial, que é de extrema importância ter todo o controle de vazão e de níveis, já que um descuido ou uma falha podem ser altamente prejudiciais ao processo, ocasionando descontroles e perdas. 
Observou-se também, em relação às simulações das fermentações, que quanto maior o teor de sólidos solúveis nas misturas açucaradas, mais forçada é a fermentação, tendo como consequência um aumento considerável no teor alcóolico do vinho.

Para um processo de fermentação alcóolica que utiliza a sedimentação como meio de recuperação do fermento, notou-se a extrema importância de uma levedura com características floculantes, pois além da força da gravidade, a sedimentação acontece de forma efetiva.

\section{REFERÊNCIAS}

ALCARDE, A. R. Fermentação. Agência Embrapa de Informação Tecnológica. Brasília. Disponível em: https://www.agencia.cnptia.embrapa.br/gestor/cana-deacucar/arvore/CONTAG01_105_22122006154841.html. Acesso em: 18 out. 2019.

AROUCA, Fábio de Oliveira. Uma Contribuição ao Estudo da Sedimentação Gravitacional em Batelada. 2007. 162 p. Tese (Doutorado em Engenharia Química) Universidade Federal de Uberlândia, Uberlândia, 2007. Disponível em: https://repositorio.ufu.br/bitstream/123456789/15096/1/FOAroucaTES01PRT.pdf. Acesso em: 18 out. 2019.

BABIC, D.; PFENNIG, A. Direct Modelling of Unit Operations on Molecular Level. Proc. 16th Eu. Symp. Computer Aided Process Eng. and 9th Int. Symp. PSE, Eds. W. Marquardt, C. Pantelides, Elsevier, p. 359-364, 2006.

CAMPOS, Edilene N. Desempenho da recentrifugação celular no processo de fermentação de etanol biocombustível em escala industrial. 2013. $46 \mathrm{f}$. Trabalho de Conclusão de Curso (Curso Superior de Tecnologia em Biocombustíveis) - Universidade Federal do Paraná, Palotina - PR, 2013. Disponível em: https://acervodigital.ufpr.br/bitstream/handle/1884/35288/Desempenho\%20da\%20recentrif ugacao $\% 20$ celular $\% 20$ no $\% 20$ processo $\% 20 \mathrm{de} \% 20$ fermentacao $\% 20 \mathrm{de} \% 20$ etanol $\% 20 \mathrm{biocu}$ mbustivel\%20em\%20esca.pdf?sequence=1\&isAllowed=y. Acesso em: 18 out. 2019.

CARVALHO, Diéury de L.; SOUZA, Marco Antônio C. de; ZEMPULSKI, Denise A. Utilização do método eletrofloculação para tratamento de efluentes industriais. Revista Nacional de Gerenciamento de Cidades, v. 03, n. 14, p. 14-28, ago. 2015.

COELHO, P. Saccharomyces cerevisiae. Disponível em: https://www.engquimicasantossp.com.br/2013/09/saccharomyces-cerevisiae.html. Acesso em: 20 out. 2019

COSTA, Palmira Fontes da (org.). Manifesto para uma nova química: o Discurso Preliminar do Traité Elementaire de Chimie de Antoine Laurent Lavoisier. Lisboa: Editora Palavrão, 2015. 
CREMASCO, Marco Aurélio. Operações Unitárias em Sistemas Particulados e Fluidomecânicos. São Paulo: Editora Blücher, 2012.

CRUZ, Mariana Lopez. Avaliação de condições operacionais na fermentação alcoólica VHG empregando diferentes cepas de Saccharomyces cerevisiae. 2019. 119 p. Tese (Doutorado em Engenharia Química) — Universidade Federal de Uberlândia, Uberlândia, 2019. Disponível em: https://repositorio.ufu.br/bitstream/123456789/24567/3/AvaliacaoCondicoesOperacionais. pdf. Acesso em: 18 out. 2019.

FOUST, A. S.; WENZEL, L. A.; CLUMP, C. W.; MAUS, L.; ANDERSEN, L. B. Princípio das Operações Unitárias. Rio de Janeiro: Editora Guanabara Dois, 1982.

GUIDINI, Carla Zanella. Fermentação Alcóolica em Batelada Alimentada Empregando Saccharomyces Cerevisiae de Características Floculantes. 2013. 148 p. Tese (Doutorado em Engenharia Química) - Universidade Federal de Uberlândia, Uberlândia, 2013. Disponível

em: https://repositorio.ufu.br/bitstream/123456789/15069/1/Carla\%20Zanella.pdf. Acesso em: 18 out. 2019.

JÚNIOR, R. N. L.; ABREU, F. O. M. S. Produtos Naturais Utilizados como Coagulantes e Floculantes para Tratamento de Águas. Revista Virtual de Química, v. 10, n. 3, p. 714, jun. 2018.

MADIGAN, Michael. Microbiologia de Brock. São Paulo: Editora Saraiva, 2010.

MEDEIROS, D.H.M. Ambientes hipersalinos no litoral semiárido brasileiro: zona estuarina do Rio Apodi - Mossoró (RN). 2016. 151 p. Dissertação (Mestrado em Geografia) -Universidade Estadual do Ceará, Fortaleza, 2016. Disponível em: http://siduece.uece.br/siduece/trabalhoAcademicoPublico.jsf?id=84225. Acesso em: 18 out. 2019.

NOVAES, L.F. Modelo para a quantificação da disponibilidade hídrica na bacia do Paracatu. 2005. 104 p. Dissertação (Mestrado em Engenharia Agrícola) - Universidade Federal de Viçosa, Viçosa, 2005. Disponível em: https://www.locus.ufv.br/bitstream/123456789/9726/1/texto\%20completo.pdf. Acesso em: 18 out. 2019.

PFENNIG, A. Distillation Simulated on Molecular Level. Molecular Simulation, v. 30, n. 6, p. 361-366, 2004. 